Article

\title{
Facile Construction of Superhydrophobic Surfaces by Coating Fluoroalkylsilane/Silica Composite on a Modified Hierarchical Structure of Wood
}

\author{
Jiajie Wang, Yingzhuo Lu, Qindan Chu, Chaoliang Ma, Lianrun Cai, Zhehong Shen * and \\ Hao Chen *
}

School of Engineering, Zhejiang A\&F University, Hangzhou 311300, China; laowangwjj0126@163.com (J.W.); tqy033201@163.com (Y.L.); 15306587705@163.com (Q.C.); qq843543030@163.com (C.M.); cailianr21@163.com (L.C.)

* Correspondence: zhehongshen@zafu.edu.cn (Z.S.); haochen@zafu.edu.cn (H.C.)

Received: 15 March 2020; Accepted: 1 April 2020; Published: 4 April 2020

\begin{abstract}
Constructing superhydrophobic surfaces by simple and low-cost methods remains a challenge in achieving the large-scale commercial application of superhydrophobic materials. Herein, a facile two-step process is presented to produce a self-healing superhydrophobic surface on wood to improve water and mildew resistance. In this process, the natural hierarchical structure of wood is firstly modified by sanding with sandpaper to obtain an appropriate micro/nano composite structure on the surface, then a fluoroalkylsilane/silica composite suspension is cast and dried on the wood surface to produce the superhydrophobic surface. Due to the full use of the natural hierarchical structure of wood, the whole process does not need complicated equipment or complex procedures to construct the micro/nano composite structure. Moreover, only a very low content of inorganic matter is needed to achieve superhydrophobicity. Encouragingly, the as-obtained superhydrophobic surface exhibits good resistance to abrasion. The superhydrophobicity can still be maintained after 45 abrasion cycles under the pressure of $3.5 \mathrm{KPa}$ and this surface can spontaneously recover its superhydrophobicity at room temperature by self-healing upon damage. Moreover, its self-healing ability can be restored by spraying or casting the fluoroalkylsilane/silica composite suspension onto this surface to replenish the depleted healing agents. When used for wood protection, this superhydrophobic surface greatly improves the water and mildew resistance of wood, thereby prolonging the service life of wood-based materials.
\end{abstract}

Keywords: superhydrophobic surfaces; self-healing; natural hierarchical microstructures; wood

\section{Introduction}

The fabrication of superhydrophobic surfaces with water contact angles (CAs) larger than $150^{\circ}$ and sliding angles less than $10^{\circ}$ has attracted extensive research attention worldwide due to its great potential in both theoretical research and practical applications, such as self-cleaning [1], anti-fouling [2], durable antibacterial uses [3], oil/water separation [4,5], gas sensing and droplet manipulation [6]. The superhydrophobic property of the surface is controlled by its chemical composition and topography. The cooperation of micro/nano scale hierarchical structures with low-surface energy materials has been the main strategy to fabricate superhydrophobic surfaces [7]. Through years of extensive efforts, many chemical and physical methods that generate superhydrophobic surfaces have been developed, such as plasma polymerization/etching [8], chemical vapor deposition [9-12], solvent-mediated phase separation [13], and polymer self-assembly [14-16]. However, some superhydrophobic surfaces are apt to lose their superhydrophobicity during practical applications since the artificial micro/nano 
hierarchical architectures are susceptible to being damaged after a slight scratch, abrasion, or even brief contact with fingers, which has hampered their widespread application. Recently, although many researchers have reported the successful fabrication of mechanically durable superhydrophobic surfaces [17-23], it is still highly desired to construct superhydrophobic surfaces by simple and low-cost methods to achieve the large-scale commercial application of superhydrophobic materials.

Wood, as a renewable resource, has great potential in decorative fields to substitute steel, stone, glass, minerals, and synthetic resin. Nevertheless, because it contains many hydrophilic groups such as hydroxyl groups, the wood is apt to absorb water, which can result in dimensional instability and attacks by microorganisms including decay fungi and mildew [24-26]. Therefore, it is of great practical significance to construct a high-performance superhydrophobic surface for the wood.

In this work, we have described a facile process to fabricate a robust self-healing superhydrophobic surface on wood with improved water and mildew resistance. In this process, the natural hierarchical structure of wood was firstly modified by sanding with sandpaper to obtain an appropriate micro/nano composite structure on the surface, then a fluoroalkylsilane/silica composite suspension was cast and dried on the wood surface to produce the superhydrophobic surface. Due to the full use of the natural hierarchical structure of wood, the whole process does not need complicated equipment or complex procedures to construct the micro/nano composite structure. Moreover, only a very low content of inorganic matter is needed to achieve superhydrophobicity. Therefore, the as-obtained superhydrophobic surface is transparent and unveils the natural grains and textures of the original surface. More importantly, benefiting from the unique micro/nano composite structure originated from the natural hierarchical structure of wood, the superhydrophobic surface exhibits robust superhydrophobic performance against physical damages. Furthermore, owing to the intrinsic porous structures of wood, the superhydrophobic surface can preserve a large number of fluoroalkylsilane moieties as the healing agent in the wood pores such as cell cavities and grooves. Once the primary top fluoroalkylsilane layer is decomposed or scratched, the internally-preserved healing agent in the wood pores will migrate to the surface to heal the superhydrophobicity at room temperature. Thus, the superhydrophobic surface exhibits good self-healing ability when damaged. And this self-healing ability can be restored by spraying or casting the fluoroalkylsilane/silica composite suspension onto the wood surface to replenish the depleted healing agents. In addition, when used for wood protection, this superhydrophobic surface greatly improves the water and mildew resistance of wood, thereby prolonging the service life of wood-based materials.

\section{Materials and Methods}

\subsection{Materials}

Ethanol (AR, $\geq 99.5 \%$ ), nano fumed silica $(99.8 \mathrm{wt} \%$, diameter: $7-40 \mathrm{~nm})$ and acetic acid (AR, $\geq 99.5 \%)$ were purchased from Shanghai Chemical Reagent Co. (China). Perfluorooctyltriethoxysilane (KH1322) and Chinese fir wood were kindly donated by Zhejiang Longyou Wood Bond Co. (China). Woodblocks with a size of $40 \times 35 \times 10 \mathrm{~mm}$ (longitudinal $\times$ radial $\times$ tangential) were obtained from the sapwood of Chinese fir (Cunninghamia lanceolata).

\subsection{Preparation of Fluoroalkylsilane/Silica Suspension}

Typically, $0.2 \mathrm{~g}$ of KH1322 (as a fluoroalkylsilane) was dissolved in $10 \mathrm{~g}$ of ethanol. The solution was mildly stirred until it became homogeneous and transparent. Then, $4 \mathrm{mg}$ silica nanoparticles (the ratio of silica to $\mathrm{KH} 1322$ was $2 \%$ ) were added into the previous solution and ultrasonically treated for one minute until the resulting fluoroalkylsilane/silica composite suspension was homogeneous.

\subsection{Preparation of Superhydrophobic Surfaces}

The woodblock was first sanded with 240-grit sandpaper under a pressure of $40 \mathrm{KN} \cdot \mathrm{m}^{-2}$ until a visible clean smooth surface was obtained. In this way, the natural hierarchical structure of wood was 
modified to obtain an appropriate micro/nano composite structure on the surface. Then, the above suspension was cast onto the wood surface $(40 \mathrm{~mm} \times 35 \mathrm{~mm})$ and heated in the oven for a certain period of time to form superhydrophobic surfaces. The dosage of KH1322 plus silica on the wood surface was calculated to be about $4 \mathrm{~g} \cdot \mathrm{m}^{-2}$. Unless specified, the heating temperature was $120^{\circ} \mathrm{C}$, and the duration of heating was 2 hours.

\subsection{Characterization}

The surface morphology was observed by scanning electronic microscopy (SEM). The VK-X 3D optical laser microscope system (OPM) was used to characterize the three-dimensional surface morphology. The roughness factor ( $\mathrm{Ra}$ ) was calculated according to JIS B0601:1994. The measurement of the surface wettability was performed using a dynamic contact angle (CA) testing instrument (OCA40, Filderstadt, Germany). CA was recorded at 30 seconds after a droplet of liquids $(5 \mu \mathrm{L})$ was placed on the surface. The sliding angle (SA) was measured by recording the tilt angle of the sample platform at which a liquid droplet $(10 \mu \mathrm{L})$ started to roll off the surface. Average water CAs were obtained on radial sections by measuring the same sample at six different positions. Fourier transform infrared spectroscopy (FTIR) measurements were carried out using a Nicolet Nexus 470 spectrometer (Thermo Fisher, Waltham, MA, USA). The chemical composition of the wood surface was measured by X-ray photoelectron spectroscopy (XPS, Perkin-Elmer PHI 5000C ECSA, Waltham, MA, USA). The abrasion resistance of the superhydrophobic surface was evaluated by dragging a piece of 240-grit sandpaper under $500 \mathrm{~g}$ of weight in one direction with a speed of $1 \mathrm{~cm} \mathrm{~s}^{-1}$ at a distance of $10 \mathrm{~cm}$ per cycle. Digital pictures were captured using a Canon Power Shot A 95 digital camera, and the optical images were obtained with the VK-9710 microscope. Unless specified, the water CA tests and characterizations such as SEM, XPS, FTIR, and OPM were carried on the radial sections of wood.

\section{Results and Discussion}

\subsection{Fabrication of Superhydrophobic Surfaces}

The process to fabricate the superhydrophobic surface was shown in Scheme 1. The raw wood was first sanded with 240-grit sandpapers to modify the natural hierarchical structure of the wood to obtain an appropriate micro/nano composite structure on the surface. Then, the homogeneous suspension of KH1322 fluoroalkylsilane and silica was cast onto the surface of the sanded wood and heated in an oven or room-dried for a certain period of time to form the superhydrophobic surface. The resulting material is denoted as coated sanded wood.

Figure 1a displays that the natural hierarchical structure of raw wood is highly uneven with a maximum height of more than $200 \mu \mathrm{m}$ (Figure 1b) and a roughness factor (Ra) of $38 \mu \mathrm{m}$. Moreover, some pores were found to be too large (the inset of Figure 1a) to support the weight of the water droplet that resulted in a homogeneous wetting, namely, Wenzel states [27]. Thus, this natural hierarchical structure is not applicable to directly construct the superhydrophobic surface. As expected, when the fluoroalkylsilane/silica suspension was cast and dried on the surface of this raw wood, the water CA on the resultant surface was only $132^{\circ}$, hence the superhydrophobicity cannot be achieved. Figure $1 \mathrm{c}$ demonstrates that a relatively uniform micro/nano hierarchical structure can be obtained by sanding the raw wood with 240-grit sandpapers. Figure $1 \mathrm{~d}$ manifests that the maximum height and Ra of the modified surface structure of sanded wood decreased to be less than $100 \mu \mathrm{m}$ and $5.69 \mu \mathrm{m}$, respectively. The air in the uniform pores can reduce contact areas between water droplets and surface, resulting in the Cassie-Baxter state [28]. Benefiting from this state, the coated surface obtained by drying the fluoroalkylsilane/silica suspension on the sanded wood exhibited a typical superhydrophobic feature with a water $\mathrm{CA}$ of $160^{\circ}$ and a sliding angle below $10^{\circ}$. 


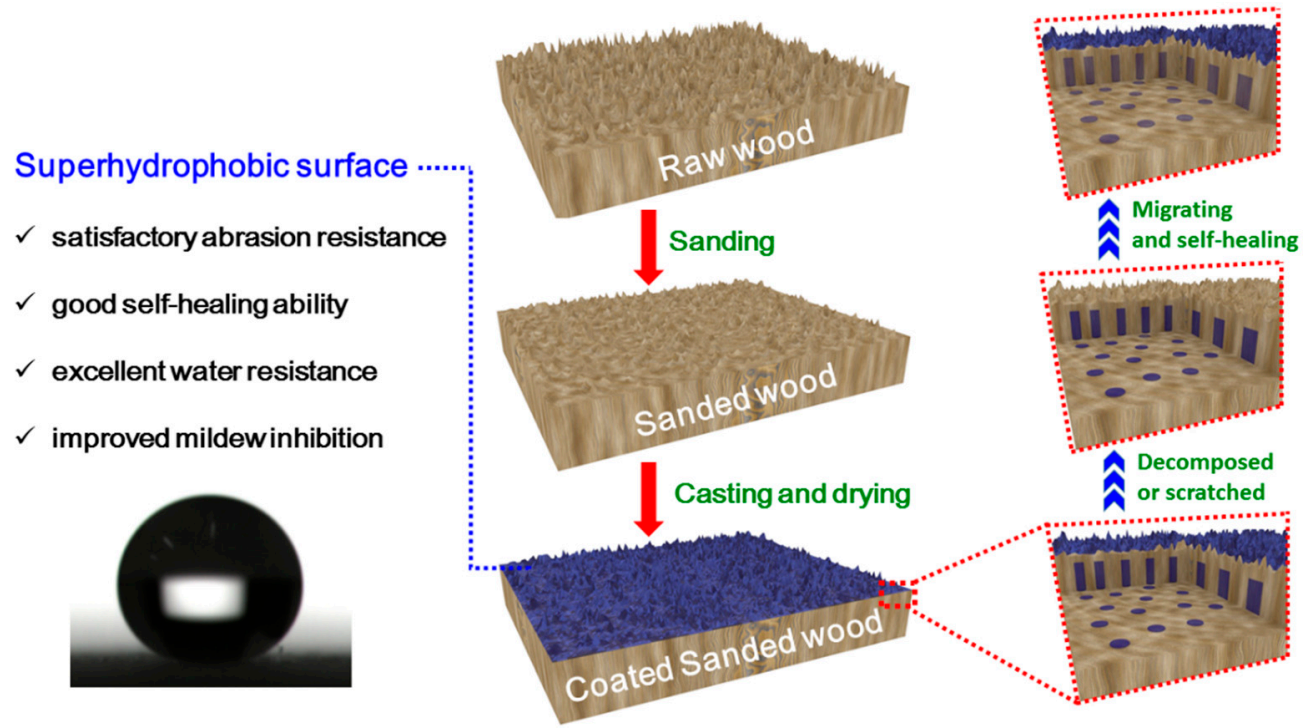

Scheme 1. Schematic procedure for the preparation of the superhydrophobic wood surface (middle) and its self-healing mechanism (right).
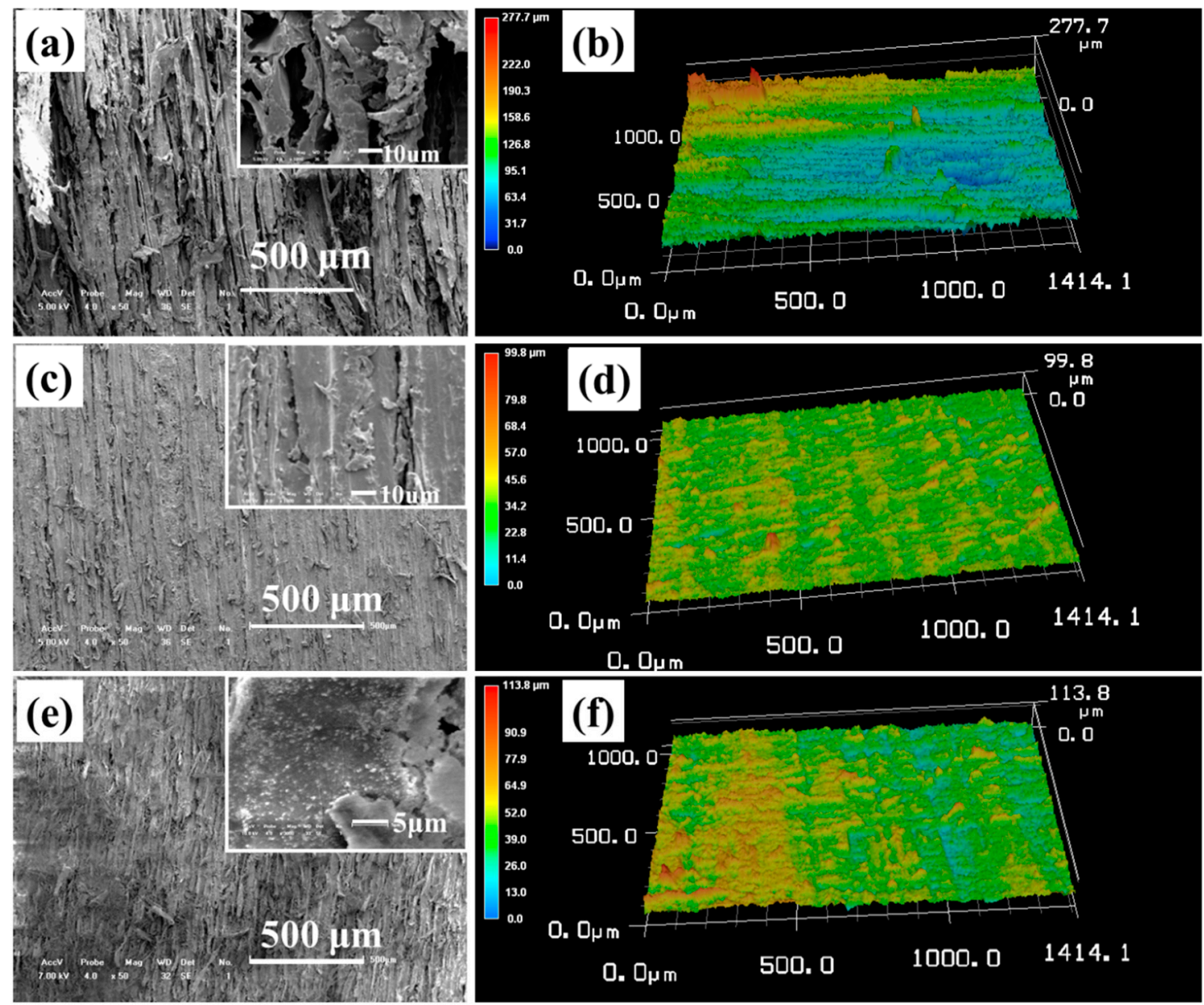

Figure 1. (a) Scanning electronic microscopy (SEM) and (b) 3D optical laser microscope system (OPM) images of raw wood. (c) SEM and (d) 3D OPM images of sanded wood. The insets are magnified SEM images with scale bars at $10 \mu \mathrm{m}$. (e) SEM and (f) 3D OPM image of sanded wood coated with KH1322 fluoroalkylsilane and silica. 
To understand the detailed formation mechanism of this superhydrophobic surface, its three-dimensional surface morphology was investigated by SEM and OPM. The low magnification SEM image of coated sanded wood in Figure 1e displays a similar micromorphology compared with that of the sanded wood without coating (Figure 1c). However, we can find some new particles on the surface in its high magnification SEM image (the inset of Figure 1e). These particles should be the silane oligomers produced by the KH1322 hydrolysis and silica particles. Their emergence led to an increase in the roughness. As a result, both the maximum height $(113.8 \mu \mathrm{m})$ and $\mathrm{Ra}(10.21 \mu \mathrm{m})$ of coated sanded wood in the OPM image of Figure $1 \mathrm{f}$ have a slight increase compared with the data of the sanded wood without coating (Figure 1d).

Usually, the raw wood surface is hydrophilic due to its naturally porous structure with abundant hydroxyl groups [25]. Thus, the chemical polarity of the surface must be changed to achieve superhydrophobicity. The comparison of FITR spectra in Figure 2 reveals that there are five new absorbance bands for the coated sanded wood compared with the raw wood. Among them, two peaks at 1267 and $617 \mathrm{~cm}^{-1}$ can be attributed to the vibrations of $\mathrm{CF}_{3}$ and $\mathrm{CF}$ groups [29]. The other three absorbance peaks at 898,805 and $467 \mathrm{~cm}^{-1}$ are ascribed to the vibrations of Si-O. It is believed that the molecular chains with these hydrophobic groups combine with the uniform micro/nano hierarchical structure of the sanded wood to achieve the construction of the superhydrophobic wood surface.

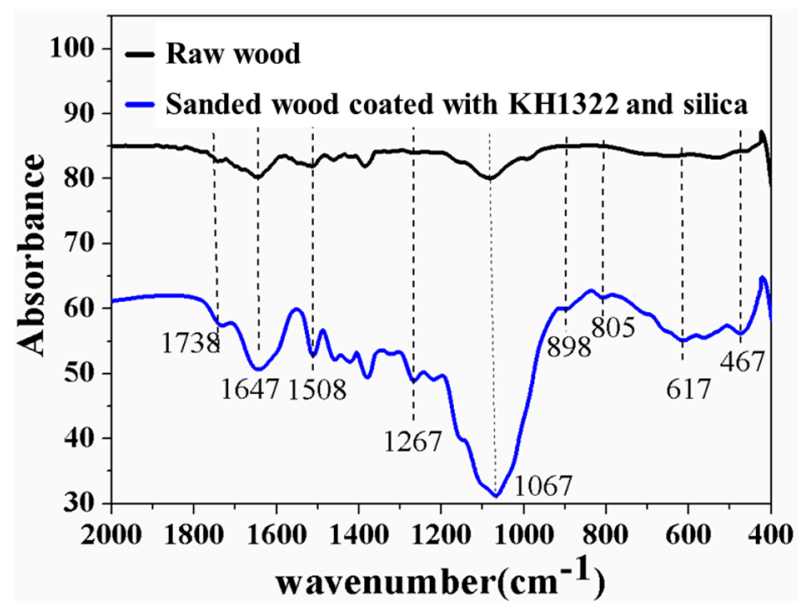

Figure 2. Comparison of Fourier transform infrared spectroscopy (FTIR) spectra between raw wood and sanded wood coated with KH1322 fluoroalkylsilane and silica.

\subsection{The Effect of Silica on the Surface Wettability}

In this work, the silica was added to prepare the hydrophobic surface. Thus, the effect of silica content on the surface wettability was investigated. It was found that the water CA increased from $152^{\circ}$ to $160^{\circ}$ when the ratio of silica to KH1322 increased from $0.5 \%$ to $2 \%$. However, when the silica ratio further elevated from $2 \%$ to $4 \%$, the water CA remained nearly unchanged at $160^{\circ}$. The silica ratio and the total consumption of KH1322 plus silica for superhydrophobic surfaces in the present study were much less than those in previous works [29]. The minimum silica ratio used in this work reached as low as $0.5 \%$, and the total consumption per unit area of KH1322 plus silica was only $4 \mathrm{~g} \cdot \mathrm{m}^{-2}$, indicating a low-cost characteristic of the preparation method.

Unlike previously reported method based on silica to prepare the superhydrophobic surface, the silica plays a major role in accelerating the hydrolysis and condensation of KH1322 in this work, rather than building micro-nano morphologies. Therefore, the superhydrophobic surface could be obtained even under a low silica ratio of $0.5 \%$. The detailed reason for the silica ratio affecting the surface wettability can be explained as follows. When the silica particles were added into KH1322 solutions, the hydrolysis of KH1322 was developed more quickly. The hydrophilic molecular chains containing C-O groups reduced and the wood surface was covered by more hydrophobic molecular chains containing $\mathrm{Si}-\mathrm{O}$ groups, resulting in an increase in the water CAs correspondingly. When the 
silica feeding ratio further increased to $2 \%$, almost all $-\mathrm{OC}_{2} \mathrm{H}_{5}$ groups from $\mathrm{KH} 1322$ were hydrolyzed to generate ethanol, which was completely removed from the wood surface during the drying process, thus the C-O groups could hardly be detected. At this point, the number of hydrophobic groups reached the maximum value. In order to confirm the above assumptions, XPS was used to analyze the element change on the wood surfaces. In Figure 3a, the C 1s XPS broad peak of sanded wood coated with $\mathrm{KH} 1322$ and $0.5 \% \mathrm{SiO}_{2}$ can be fitted to four peaks with binding energies of 283.8, 285.6, 287.3 and $290.9 \mathrm{eV}$, which can be indexed to the functional groups of Si-C, C-C, C-O, and $\mathrm{CF}_{2}$, respectively [30]. Here, the ratio of hydrophilic carbons (C-O groups) to all carbon atoms was calculated to be $3.46 \%$ based on the peak areas in Figure 3a. However, for the sanded wood coated with KH1322 and 2\% silica, the hydrophobic $\mathrm{C}$ atoms ( $\mathrm{Si}-\mathrm{C}, \mathrm{C}-\mathrm{C}$, and $\mathrm{CF}_{2}$ groups) can account for nearly $100 \%$ of all $\mathrm{C}$ atoms. Hence, the additional increase in the silica ratio to $4 \%$ no longer increased the ratio of hydrophobic groups, so the water CAs did not increase further.
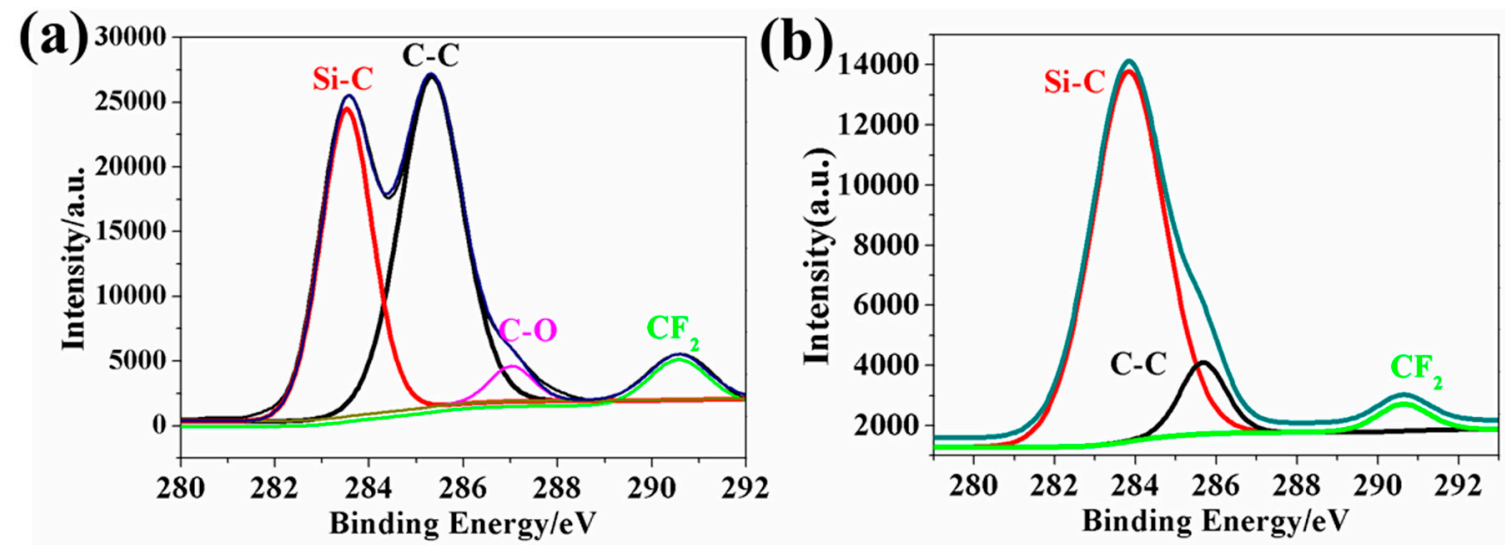

Figure 3. C 1s X-ray photoelectron spectroscopy (XPS) spectra of (a) sanded wood coated with KH1322 and $0.5 \% \mathrm{SiO}_{2}$ and $(\mathbf{b})$ sanded wood coated with $\mathrm{KH} 1322$ and $2.0 \% \mathrm{SiO}_{2}$.

\subsection{The Effect of Drying Temperatures on Surface Wettability}

Usually, the drying temperature is a key factor that affects the formation of the coating. Therefore, the influence of drying temperature on the surface wettability was also researched. As shown in Figure $4 \mathrm{a}$, the water $\mathrm{CA}$ increased from $157^{\circ}$ and $160^{\circ}$ to $170^{\circ}$ with the elevation of the drying temperature from $100^{\circ} \mathrm{C}$ and $120^{\circ} \mathrm{C}$ to $130^{\circ} \mathrm{C}$. When the drying temperature was increased again to $140^{\circ} \mathrm{C}$, the water $\mathrm{CA}$ decreased slightly from $170^{\circ}$ to $167^{\circ}$. The previous $\mathrm{CA}$ increase should result from the reduction of hydrophilic $\mathrm{C}-\mathrm{O}$ groups. It is believed that the increase in the drying temperature from $100{ }^{\circ} \mathrm{C}$ to $120^{\circ} \mathrm{C}$ accelerated the hydrolysis of $\mathrm{KH} 1322$. More $-\mathrm{OC}_{2} \mathrm{H}_{5}$ groups of $\mathrm{KH} 1322$ reacted with the water to release ethanol vapour. Therefore, the hydrophilic C-O groups reduced correspondingly, as illustrated by the diminished peak intensity of $\mathrm{C}-\mathrm{O}$ groups at $1271 \mathrm{~cm}^{-1}$ (Figure $4 \mathrm{~b}$ ). When the drying temperature was further elevated to $130^{\circ} \mathrm{C}$, almost all $-\mathrm{OC}_{2} \mathrm{H}_{5}$ groups of $\mathrm{KH} 1322$ were hydrolyzed to generate ethanol vapour. The virtual disappearance of the $\mathrm{C}-\mathrm{O}$ signal in Figure $4 \mathrm{~b}$ demonstrates the removal of more hydrophilic groups. Moreover, the adsorption of hydrophobic groups (Si-O at 810 and $470 \mathrm{~cm}^{-1}$ ) reached the maximum signal. These facilitate the formation of the superhydrophobic surface with a larger water CA. It could be inferred that the drying temperature of $130{ }^{\circ} \mathrm{C}$ is high enough to achieve the complete hydrolysis of KH1322. Thus, when the temperature further increased to $140{ }^{\circ} \mathrm{C}$, the ratio of hydrophobic groups on the wood surfaces no longer increased, with the result that the water CA would not increase correspondingly. 

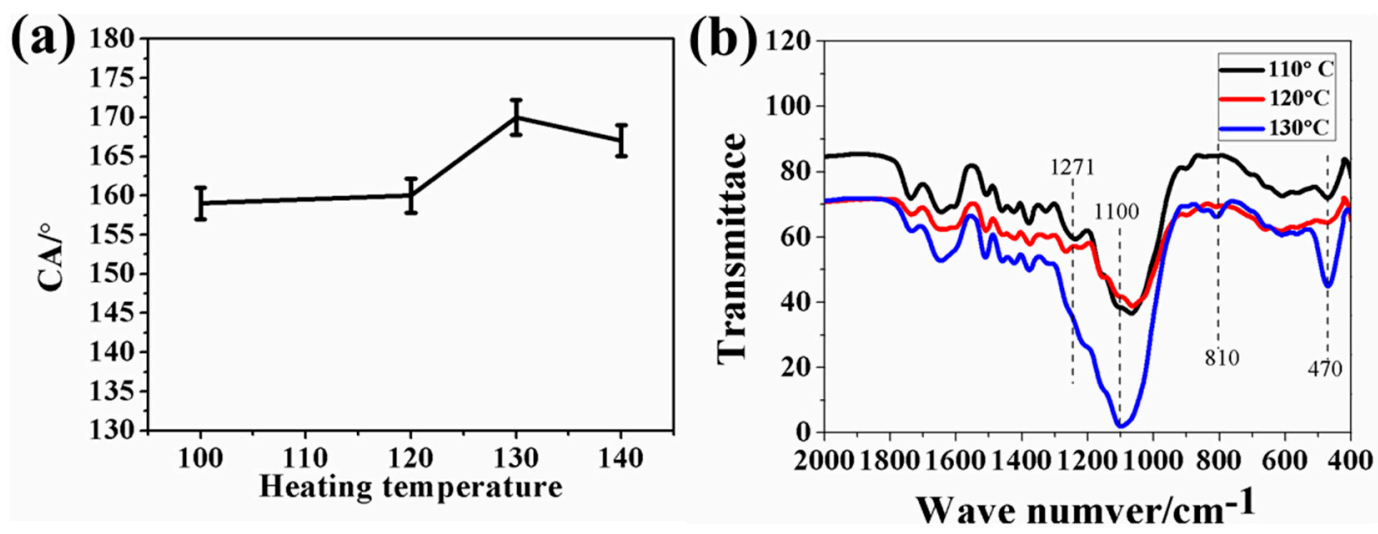

Figure 4. (a) The water contact angles (Cas) of the surfaces of coated sanded wood obtained at different drying temperatures, (b) Comparison of FTIR spectra of sanded woods coated with KH1322 fluoroalkylsilane and silica obtained at different drying temperatures.

Considering that hours of high-temperature drying may induce damages to some wood, the drying at room temperature $\left(25^{\circ} \mathrm{C}\right)$ was also tried to prepare the hydrophobic surface. It was found that the water $\mathrm{CA}$ on the as-obtained surface increased from $75^{\circ}$ to $155^{\circ}$ when the drying time was extended from 2 hours to 8 hours. This result revealed that the fabrication of a superhydrophobic surface on the wood can also be achieved at room temperature when the drying time is long enough. This suggests that the method can be extended to produce superhydrophobic surfaces for thermally unstable wood products.

\subsection{Mechanical Robustness and Self-Healing of Superhydrophobic Surfaces}

One obstacle to the widespread practical applications of superhydrophobic surfaces is the lack of enough robustness. To investigate the abrasion resistance of the as-obtained superhydrophobic surface, under the loading of 500 grams (pressure: $3.5 \mathrm{KPa}$ ), the hydrophobic surface of the coated sanded wood was oriented toward 240-grit sandpaper and moved a distance of $10 \mathrm{~cm}$ (each cycle) in a straight line, as shown in Figure 5a. Then, the water CAs of the resulting wood surface were tested. This process was repeated for 45 cycles, and the test results of water CAs were recorded in Figure 5b. One can see that after 45 cycles, the water CA was able to retain a high value of $153^{\circ}$, and the sliding angle was still less than $10^{\circ}$, indicating that the surface of the coated sanded wood maintained its superhydrophobicity. These results demonstrate the satisfactory abrasion resistance of the as-prepared superhydrophobic surface.

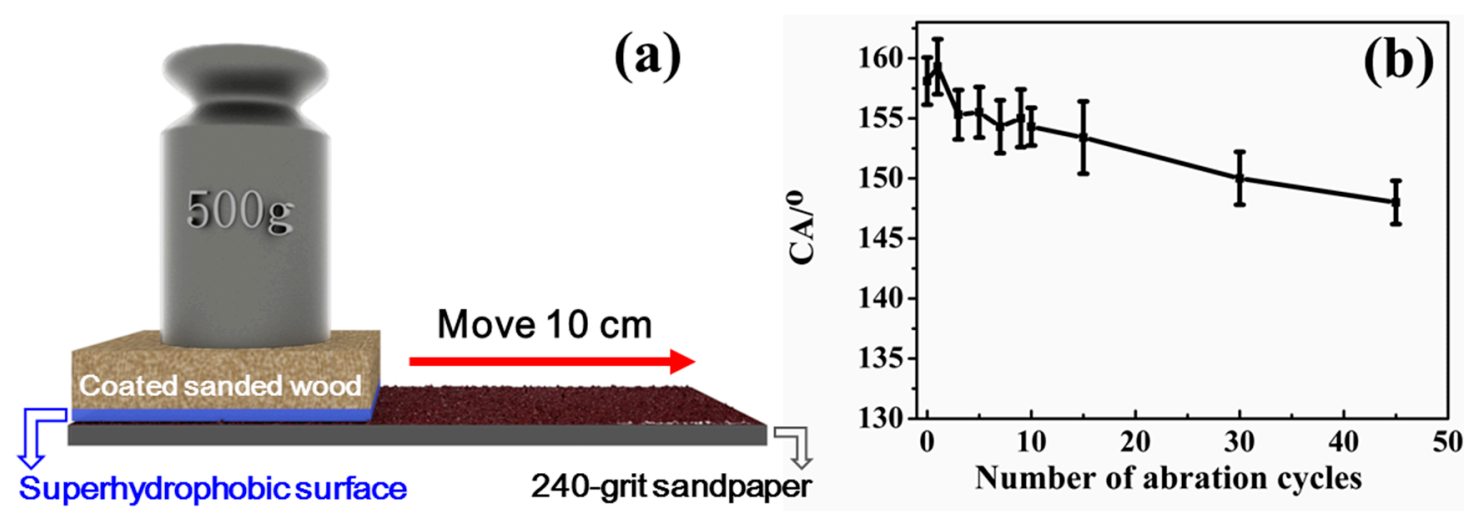

Figure 5. (a) Illustration of the abrasion resistance test for the superhydrophobic surface. (b) Water CAs as a function of the number of abrasion cycles.

As an important indicator affecting service life, the self-healing ability of the superhydrophobic surface was examined by alkali etching. After it was soaked in alkali solution for two hours, 
the water CA of the resulting surface decreased from $160^{\circ}$ to $0^{\circ}$, indicating that this surface had lost its superhydrophobicity. However, after this damaged surface was exposed in an ambient environment for 8 hours, its water CA and sliding angles returned to $160^{\circ}$ and $<10^{\circ}$, respectively, demonstrating that the original superhydrophobicity of the damaged surface was restored. The recovery of superhydrophobicity should be attributed to the unique inherent porous structure of wood. This intrinsic porous structure can preserve a large number of fluoroalkylsilane moieties as healing agents in wood pores (such as cell cavities and grooves) beneath the superhydrophobic surface. Once the primary top fluoroalkylsilane layer is decomposed or scratched, the internal preserved healing agents in the cell cavities and grooves will migrate to the wood surface (as illustrated by the right part of Scheme 1) to minimize the surface free energy due to the exposure to the hydrophobic air [31,32]. As a result, the superhydrophobicity is healed at room temperature. In this way, the damaged surface recovered its superhydrophobicity at room temperature when the time duration was long enough for the healing agents in pores to migrate onto the wood surface. As displayed in Figure 6a, the etching-healing process can be repeated for nine cycles without decreasing the superhydrophobicity of the self-healed surface. It is believed that the robust internal porous microstructure of wood is essential for the recovery of superhydrophobicity as shown in Figure $6 b, c$. In addition, it was found that when the temperature increased to $100{ }^{\circ} \mathrm{C}$ and $140{ }^{\circ} \mathrm{C}$, the recovery time of the superhydrophobicity reduced to $2 \mathrm{~h}$ and $1 \mathrm{~h}$, respectively. This indicates that this self-healing is temperature-dependent, with a more accelerated self-healing process under higher temperatures and vice versa. At present, the self-healing of the as-constructed superhydrophobic surface can be accomplished at room temperature. Thus, this self-healing can be applied to some wooden decorative materials that are sensitive to heat and ultraviolet radiation. Furthermore, if repeated self-healing runs out of healing agents, the suspension of KH1322 fluoroalkylsilane and silica can be cast and dried onto the surface again to replenish the healing agents.
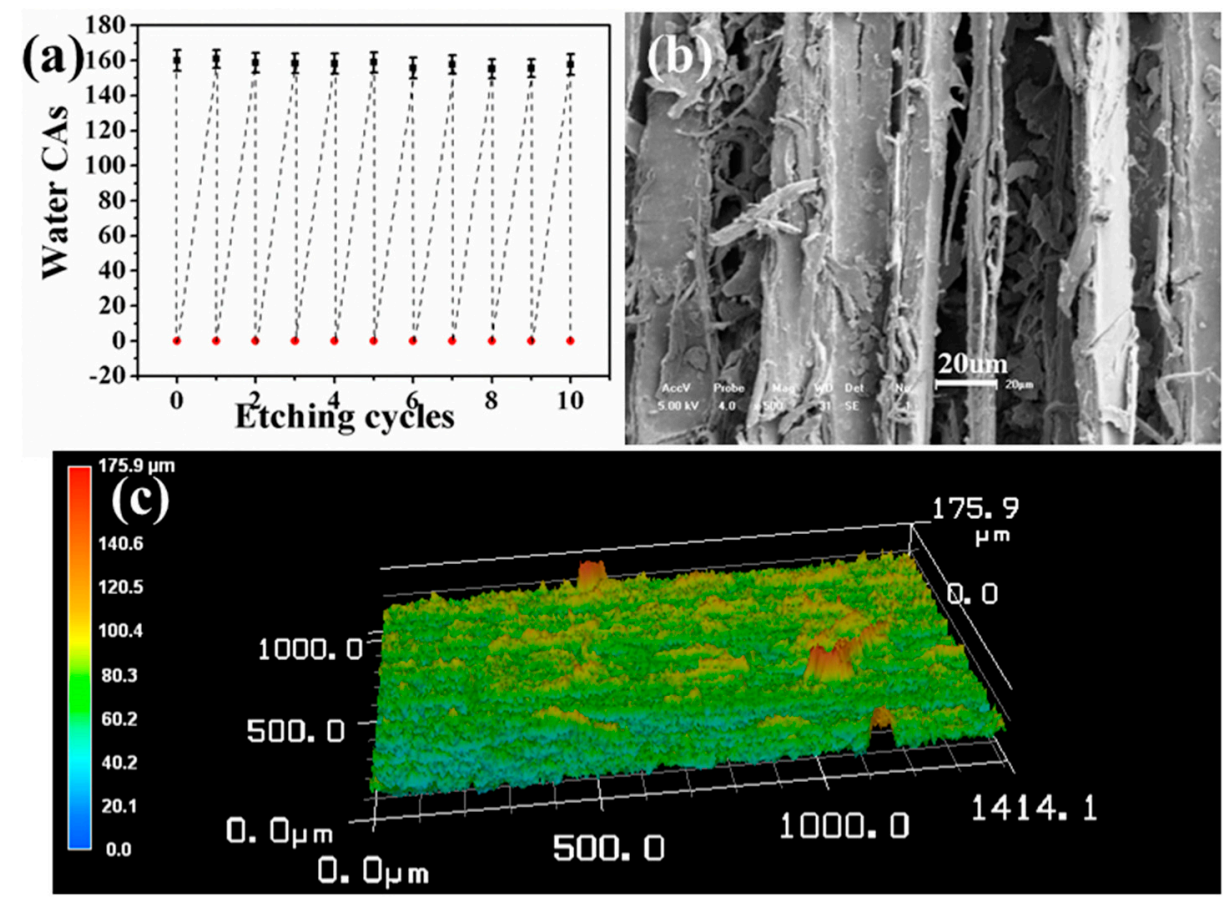

Figure 6. (a) Water CAs of the surface after repeated alkaline etching and self-healing at room temperature. (b) SEM and (c) 3D OPM images of the surface of coated sanded wood after alkaline etching.

\subsection{Improvement in Water and Mildew Resistance of Superhydrophobic Surfaces}

As a natural biomass material with many hydrophilic groups, raw wood is apt to absorb water and swell in dimension when in contact with water [24]. In order to simulate the rinse effect of rainwater 
on the surface of outdoor wood products, the as-obtained superhydrophobic surface of coated sanded wood was washed by running water for 20 minutes (Figure 7a). No residual water can be observed on the superhydrophobic surface after this process (Figure $7 \mathrm{~b}$ ). By contrast, excessive water remained on the surface of raw wood after the same treatment (Figure 7c-d). These results indicate the excellent water resistance of the as-constructed superhydrophobic surface.
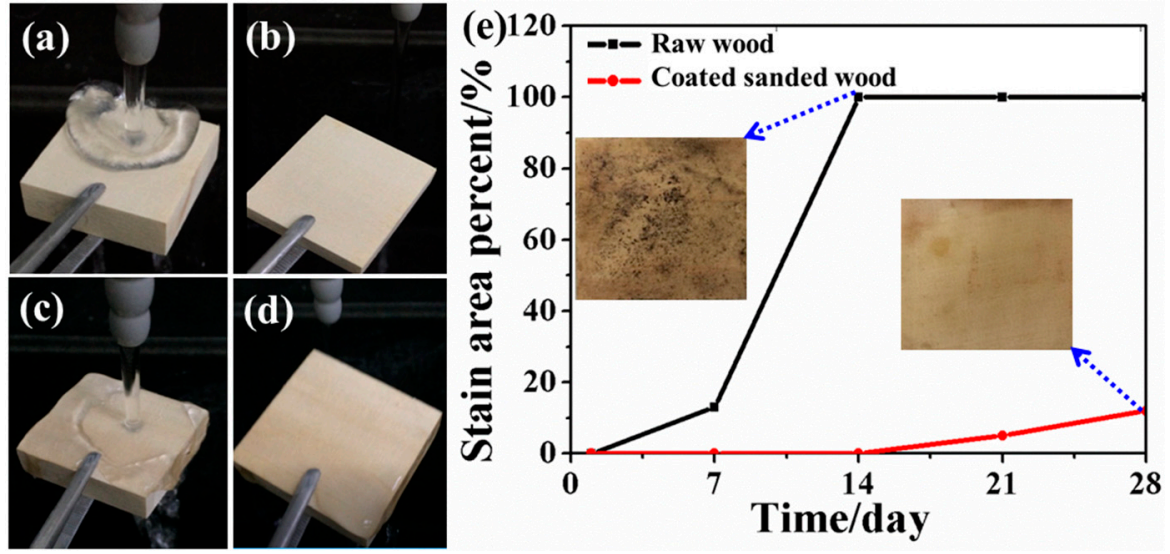

Figure 7. Photographs of the superhydrophobic wood surface (a) during water washing and (b) after water washing. Photographs of the raw wood surface (c) during water washing and (d) after water washing. (e) Comparison of mildew infection on the surface of raw wood and coated sanded wood in a humid environment.

Wood contains protein, starch, cellulose, etc., which can provide nutrients for microbial growth, so it is easily infected by mildew, especially when the wood surface is wet. Here, the mildew resistance ability of the as-prepared superhydrophobic wood surface was studied and compared with that of the raw wood surface. The results in Figure 7 e demonstrate that about $13 \%$ of the surface area of the raw wood had been infected by mildew on the 7 th day when it was placed in an environment with a humidity of $90 \%$ and a temperature of $30{ }^{\circ} \mathrm{C}$, and the percentage of the infected area increased to $100 \%$ on the 14th day. By contrast, the coated sanded wood with the superhydrophobic surface was not infected by mildew until the 14 th day and only $12 \%$ of its surface was infected by mildew on the 28 th day under the same environment. The improved mildew resistance could be due to the fact that the superhydrophobic surface repelled water and reduced water adsorption thereby inhibiting the growth of mildew. In addition, this surface can maintain its superhydrophobic ability as shown by only minimal contact angle fluctuations (Figure 8) after a long period of high-intensity UV irradiation which demonstrates the fine UV durability of this superhydrophobic surface. Therefore, it is highly promising to employ this superhydrophobic surface to prolong the service life of wood-based materials.

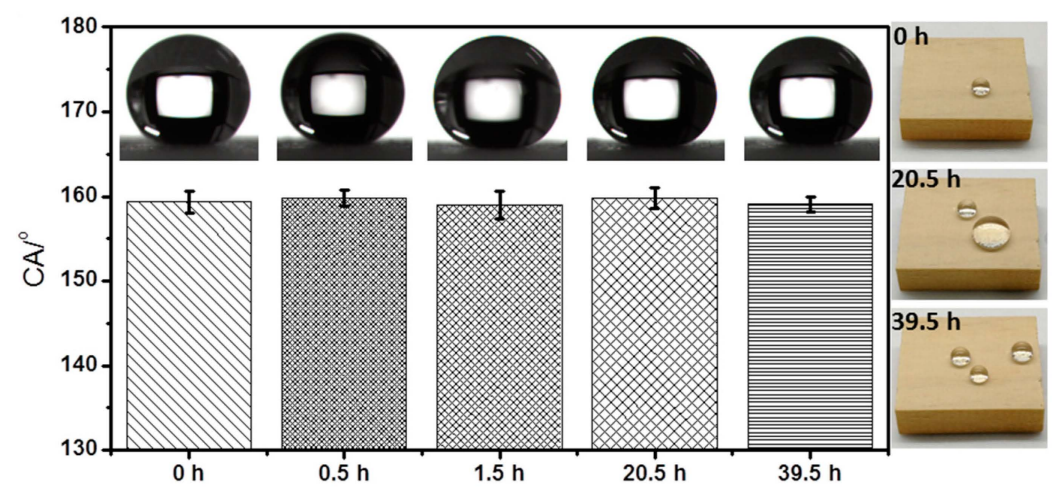

Figure 8. Water CAs and photographs of the coated sanded wood surface after being irradiated with $365 \mathrm{~nm}$ UV lamp $\left(11.6 \mathrm{~mW} \cdot \mathrm{cm}^{-2}\right)$ for different times. 


\section{Conclusions}

In this work, a novel superhydrophobic surface has been fabricated successfully by casting and drying a composite suspension of KH1322 and silica on the modified hierarchical structure of wood. Due to the full use of the natural hierarchical structure of wood, the whole process needs neither complicated equipment nor complex procedures to construct the micro/nano composite structure. Only a very low content of inorganic matter is needed to achieve superhydrophobicity. Furthermore, the fabrication of a superhydrophobic surface can be achieved at room temperature. More importantly, the as-prepared superhydrophobic surface exhibits a satisfactory resistance to abrasion and is able to self-heal at room temperature upon damage. If the healing agents are depleted, the surface can restore its self-healing ability by casting the fluoroalkylsilane/silica composite suspension to replenish the healing agents. When used for wood protection, this superhydrophobic surface greatly improves both mildew inhibition and water resistance of wood, thereby prolonging the service life of wood-based materials. The excellent performance of the as-constructed superhydrophobic surface, the facile and environmentally friendly fabrication process, and the low cost, make this method highly suitable for the protection of various wood-based materials.

Author Contributions: Conceptualization, Z.S.; Data curation, J.W.; Formal analysis, C.M.; Funding acquisition, Z.S. and H.C.; Investigation, J.W., Y.L., Q.C. and C.M.; Methodology, J.W.; Project administration, Z.S. and H.C.; Resources, Q.C. and L.C.; Supervision, Z.S. and H.C.; Validation, L.C.; Visualization, Y.L.; Writing-original draft, Z.S.; Writing - review and editing, H.C. All authors have read and agreed to the published version of the manuscript.

Funding: This work was supported by the Zhejiang Provincial Key Research and Development Project (2019C02037), National Key Project (2017YFD0601105), Zhejiang Provincial Natural Science Foundation of China (LY20E020004), Zhejiang A\&F University Scientific Research Training Program for Undergraduates (KX20180113), Jiangsu North Special Project from Jiangsu Suqian (BN2016176), and 151 Talent Project of Zhejiang Province.

Conflicts of Interest: The authors declare no conflict of interest.

\section{References}

1. Lu, Y.; Sathasivam, S.; Song, J.; Crick, C.R.; Carmalt, C.J.; Parkin, I.P. Robust self-cleaning surfaces that function when exposed to either air or oil. Science 2015, 347, 1132-1135. [CrossRef] [PubMed]

2. Hou, X.; Hu, Y.; Grinthal, A.; Khan, M.; Aizenberg, J. Liquid-based gating mechanism with tunable multiphase selectivity and antifouling behaviour. Nature 2015, 519, 70-73. [CrossRef] [PubMed]

3. Wu, M.; Ma, B.; Pan, T.; Chen, S.; Sun, J. Silver-nanoparticle-colored cotton fabrics with tunable colors and durable antibacterial and self-healing superhydrophobic properties. Adv. Funct. Mater. 2015, 26, 569-576. [CrossRef]

4. Zhang, X.; Li, Z.; Liu, K.; Jiang, L. Bioinspired multifunctional foam with self-cleaning and oil/water separation. Adv. Funct. Mater. 2013, 23, 2881-2886. [CrossRef]

5. Ruan, C.; Ai, K.; Li, X.; Lu, L. A Superhydrophobic sponge with excellent absorbency and flame retardancy. Angew. Chem. Int. Ed. 2014, 53, 5556-5560. [CrossRef] [PubMed]

6. Liu, Y.; Wang, X.; Fei, B.; Hu, H.; Lai, C.; Xin, J.H. Bioinspired, Stimuli-responsive, multifunctional superhydrophobic surface with directional wetting, adhesion, and transport of water. Adv. Funct. Mater. 2015, 25, 5047-5056. [CrossRef]

7. Hooda, A.; Goyat, M.S.; Pandey, J.K.; Kumar, A.; Gupta, R. A review on fundamentals, constraints and fabrication techniques of superhydrophobic coatings. Prog. Org. Coat. 2020, 142, 105557. [CrossRef]

8. Youngblood, J.P.; McCarthy, T.J. Ultrahydrophobic polymer surfaces prepared by simultaneous ablation of polypropylene and sputtering of poly(tetrafluoroethylene) using radio frequency plasma. Macromolecules 1999, 32, 6800-6806. [CrossRef]

9. Folkers, J.P; Laibinis, P.E.; Whitesides, G.M. Self-assembled monolayers of alkanethiols on gold: Comparisons of monolayers containing mixtures of short- and long-chain constituents with methyl and hydroxymethyl terminal groups. Langmuir 1992, 8, 1330-1341. [CrossRef]

10. Sharma, A.; Reiter, G. Instability of thin polymer films on coated substrates: Rupture, dewetting, and drop formation. J. Colloid Interf. Sci 1996, 178, 383-399. [CrossRef] 
11. Shon, Y.-S.; Lee, S.; Colorado, R.; Perry, S.S.; Lee, T.R. Spiroalkanedithiol-Based SAMS reveal unique insight into the wettabilities and frictional properties of organic thin films. J. Am. Chem. Soc. 2000, 122, 7556-7563. [CrossRef]

12. Miyauchi, M.; Kieda, N.; Hishita, S.; Mitsuhashi, T.; Nakajima, A.; Watanabe, T.; Hashimoto, K. Reversible wettability control of $\mathrm{TiO}_{2}$ surface by light irradiation. Surf. Sci. 2002, 511, 401-407. [CrossRef]

13. Mutel, B.; Taleb, A.B.; Dessaux, O.; Goudmand, P.; Gengembre, L.; Grimblot, J. Characterization of mixed zinc-oxidized zinc thin films deposited by a cold remote nitrogen plasma. Thin Solid Films 1995, 266, 119-128. [CrossRef]

14. Gu, Z.-Z.; Uetsuka, H.; Takahashi, K.; Nakajima, R.; Onishi, H.; Fujishima, A.; Sato, O. Structural color and the lotus effect. Angew. Chem. Int. Ed. 2003, 42, 894-897. [CrossRef] [PubMed]

15. Wang, J.; Wen, Y.; Feng, X.; Song, Y.; Jiang, L. Control over the wettability of colloidal crystal films by assembly temperature. Macromol. Rapid Commun. 2006, 27, 188-192. [CrossRef]

16. Wang, J.; Wen, Y.; Hu, J.; Song, Y.; Jiang, L. Fine Control of the wettability transition temperature of colloidal-crystal films: From superhydrophilic to superhydrophobic. Adv. Funct. Mater. 2007, 17, 219-225. [CrossRef]

17. Deng, X.; Mammen, L.; Butt, H.J.; Vollmer, D. Candle soot as a template for a transparent robust superamphiphobic coating. Science 2012, 335, 67-70. [CrossRef]

18. Deng, X.; Mammen, L.; Zhao, Y.; Lellig, P.; Müllen, K.; Li, C.; Butt, H.J.; Vollmer, D. Transparent, thermally stable and mechanically robust superhydrophobic surfaces made from porous silica capsules. Adv. Mater. 2011, 23, 2962-2965. [CrossRef]

19. Latthe, S.; Terashima, C.; Nakata, K.; Sakai, M.; Fujishima, A. Development of sol-gel processed semi-transparent and self-cleaning superhydrophobic coatings. J. Mater. Chem. A 2014, 2, 5548-5553. [CrossRef]

20. Geng, Z.; He, J.; Xu, L.; Yao, L. Rational design and elaborate construction of surface nano-structures toward highly antireflective superamphiphobic coatings. J. Mater. Chem. A 2013, 1, 8721-8724. [CrossRef]

21. Chen, L.; Sun, X.; Hang, J.; Jin, L.; Shang, D.; Shi, L. Large-scale fabrication of robust superhydrophobic coatings with high rigidity and good flexibility. Adv. Mater. Interfaces 2016, 3, 1500718. [CrossRef]

22. Liao, Y.; Zheng, G.; Huang, J.J.; Tian, M.; Wang, R. Development of robust and superhydrophobic membranes to mitigate membrane scaling and fouling in membrane distillation. J. Membrane Sci. 2020, 601, 117962. [CrossRef]

23. Kobina Sam, E.; Kobina Sam, D.; Lv, X.; Liu, B.; Xiao, X.; Gong, S.; Yu, W.; Chen, J.; Liu, J. Recent development in the fabrication of self-healing superhydrophobic surfaces. Chem. Eng. J. 2019, 373, 531-546. [CrossRef]

24. Shen, Y.; Yitian, W.; Zhehong, S.; Hao, C. Fabrication of Self-healing superhydrophobic surfaces from water-soluble polymer suspensions free of inorganic particles through polymer thermal reconstruction. Coatings 2018, 8, 144. [CrossRef]

25. Lewin, M.; Goldstein, I.S. Wood Structure and Composition. Science 1991, 152, 500-502. [CrossRef]

26. Barbero-López, A.; Chibily, S.; Tomppo, L.; Salami, A.; Ancin-Murguzur, F.J.; Venäläinen, M.; Lappalainen, R.; Haapala, A. Pyrolysis distillates from tree bark and fibre hemp inhibit the growth of wood-decaying fungi. Ind. Crop. Prod. 2019, 129, 604-610. [CrossRef]

27. Wenzel, R.N. Resistance of solid surfaces to wetting by water. Ind. Eng. Chem. 1936, 28, 988-994. [CrossRef]

28. Cassie, A.B.D.; Baxter, S. Wettability of porous surfaces. Trans. Faraday Soc. 1944, 40, 546-551. [CrossRef]

29. Fu, Q.; Wu, X.; Kumar, D.; Ho, J.W.; Kanhere, P.D.; Srikanth, N.; Liu, E.; Wilson, P.; Chen, Z. Development of sol-gel icephobic coatings: Effect of surface roughness and surface energy. ACS Appl. Mater. Interfaces 2014, 6, 20685-20692. [CrossRef]

30. Esteves, A.C.C.; Luo, Y.; van de Put, M.W.P.; Carcouët, C.C.M.; With, G.D. Self-replenishing dual structured superhydrophobic coatings prepared by drop-casting of an all-in-one dispersion. Adv. Funct. Mater. 2014, 24, 986-992. [CrossRef] 
31. Wang, H.; Xue, Y.; Ding, J.; Feng, L.; Wang, X.; Lin, T. Durable, Self-healing superhydrophobic and superoleophobic surfaces from fluorinated-decyl polyhedral oligomeric silsesquioxane and hydrolyzed fluorinated alkyl silane. Angew. Chem. Int. Ed. 2011, 50, 11433-11436. [CrossRef] [PubMed]

32. Li, Y.; Chen, S.; Wu, M.; Sun, J. All spraying processes for the fabrication of robust, self-healing, superhydrophobic coatings. Adv. Mater. 2014, 26, 3344-3348. [CrossRef] [PubMed]

(c)

(C) 2020 by the authors. Licensee MDPI, Basel, Switzerland. This article is an open access article distributed under the terms and conditions of the Creative Commons Attribution (CC BY) license (http://creativecommons.org/licenses/by/4.0/). 